\title{
A APLICABILIDAdE DE POLÍTICAS DE SEGURANÇA PÚBLICA SOB A VERTENTE GARANTISTA NO DIREITO PENAL BRASILEIRO
}

\author{
Germana da Silva Leal ${ }^{1}$
}

\begin{abstract}
RESUMO
Este trabalho propõe uma reflexão sobre a atual conformação do Direito Penal brasileiro no que concerne à efetivação de políticas criminais de segurança pública capazes de diminuir a distância entre o texto normativo e a realidade cotidiana. Em outros termos busca, conduzir uma reflexão acerca da necessidade de se implementar políticas de segurança embasadas na teoria garantista, a qual, em sua essência, prima pela validade e efetividade das normas dentro do ordenamento jurídico tendo como alicerce o respeito pela pessoa humana, inclusive quanto ao que se refere à não tolerância da criminalidade e violência dentro da sociedade. Explana ainda a necessidade de uma atuação planejada na aplicação do direito penal capaz de, como ultima ratio, utilizar os mecanismos instrumentais, ou seja, as políticas públicas de segurança aptas a tutelar efetivamente os bens jurídicos preservados no texto constitucional.
\end{abstract}

Palavras-chave: Política criminal. Segurança pública. Garantismo.

\begin{abstract}
This paper proposes a reflection on the current configuration of the brazilian Penal Law in relation to the enforcement of criminal policy of public security capable of reducing the distance between the normative text and everyday reality. In other terms, search lead a discussion about the need to implement security policies based on the theory guarantees, which, in its essence raw material for the validity and effectiveness of the standards within the legal system having as a foundation to respect the human person including the with regard to the non tolerance of crime and violence within society. It elaborates the need for an operation planned for the application of the criminal law capable of, as ultima ratio, use of the mechanisms instrumental, in the words, the policies of safety which are able to protect effectively the legal assets preserved in the constitutional text.
\end{abstract}

\footnotetext{
${ }^{1}$ Advogada, graduada em Direito pela Pontifícia Universidade Católica de Goiás - PUC-GO (2008); especialista em Docência Universitária pela Faculdade Estácio de Sá de Goiás (2008); especialista em Direito Penal e Processual Penal pela Universidade Estácio de Sá (RJ) (2010) e em Direito Público pela UNIDERP/LFG (2010). Telefones: 628201 4325/9107 1473; e-mail: germana_leal@hotmail.com.
} 
Key words: Criminal policy. Policies. Guarantees.

\section{INTRODUÇÃO}

O presente trabalho indaga se as políticas criminais de segurança pública criadas sob a ótica da vertente garantista são capazes de diminuir a distância entre o texto normativo e a realidade prática do Direito Penal brasileiro. Para isso, faz-se necessário o esclarecimento acerca das políticas públicas, ou seja, o conjunto de ações coletivas voltadas para a garantia dos direitos sociais, configurando o compromisso público que vise a atender determinada demanda em diversas áreas ao expressar aquilo que é do âmbito privado em ações coletivas no espaço público.

Ao se falar em políticas públicas, em determinado momento, pensa-se no significado da ação estatal com vista à obtenção de um fim, mais especificamente na concretização dos direitos fundamentais. Enquanto em outro, demonstra-se todo o conjunto de ações, incluídas as de planejamento e as ações executivas de atuação por parte do Estado.

Nesse sentido, a pesquisa aborda a política criminal como tipo de política pública e procura, com isso, conceituá-la demonstrando suas características. Além de definir política de segurança pública dando exemplos destas, expõe as acepções, princípios e críticas da doutrina garantista por meio da demonstração da atual conformação do Direito Penal brasileiro. Além, é claro, de abordar a necessidade das mesmas dentro do contexto social no que concerne, principalmente, à adoção de mecanismos que possibilitem a contenção da violência.

Portanto, dentro do universo das políticas criminais são escolhidas como objeto de estudo, as políticas de segurança pública. Estas, por sua vez, são abordadas com base na imprescindível observância da segurança pública como dever do Estado e direito da sociedade, além de serem vistas como o escopo do garantismo penal, ou seja, a doutrina defendida por Luigi Ferrajoli.

Nesse contexto, serão demonstradas as características, princípios norteadores e acepções, assim como as principais críticas em torno da referida doutrina. Cuida-se mais especificamente, neste ponto, da segunda acepção garantista que trata da validade e 
efetividade no que se refere à aplicação de políticas de segurança que realmente sejam concretizadas, isto é, que além de válidas sejam efetivas e, consequentemente, tenham por finalidade diminuir a distância entre a norma e a prática.

Fica claro que a presente pesquisa possui a relevância de propor, sobretudo, uma reflexão e análise acerca da possível consequência da adoção de políticas de segurança pública sob a ótica da vertente garantista da validade e efetividade no Direito Penal brasileiro, uma vez que somente por meio da efetivação de políticas capazes de reprimir a ação criminosa com base nos princípios constitucionais contidos no bojo da Constituição da República brasileira é que se poderá contar com um Direito Penal capaz de se antecipar ao crime e ainda utilizar a melhor maneira - tanto para a sociedade como para o delinquente dos instrumentos punitivos frente à infração cometida.

\section{POLÍTICAS PÚBLICAS GARANTISTAS}

\subsection{Política pública}

Em decorrência da ausência de um conceito jurídico de políticas públicas este encontra amparo nas ciências Política ou da Administração Pública servindo, portanto, de guia aos juristas. Segundo Bucci (2006), trata-se de um programa de ação governamental resultante de um conjunto de processos juridicamente regulados, o qual visa a coordenar os meios à disposição do Estado e às atividades privadas, para a realização de objetivos socialmente relevantes e, politicamente, determinados.

Parte primeiramente da noção de política, esta não somente vista como a resolução pacífica de conflitos, mas também como uma atividade ou ainda um conjunto organizado de normas e atos tendentes à realização de um objetivo determinado (COMPARATO, 1997).

Nesse sentido, observa-se que o conceito de política pública perpassa, então, pelo de política que, por sua vez, envolve detidamente em seu bojo as implicações relacionadas com a tomada de decisões. Ou seja, no contexto das políticas públicas há a presença de decisões políticas.

Segundo Maria das Graças Rua (1998), as políticas públicas, (policies) em inglês, são resultantes da atividade política (politics). Conforme esta autora, as políticas públicas normalmente envolvem não só uma decisão, bem como um conjunto delas, compreendem 
[...] diversas ações estrategicamente selecionadas para implementar as decisões tomadas. [...] uma decisão política corresponde a uma escolha dentre um leque de alternativas, conforme a hierarquia das preferências dos atores envolvidos expressando [...] uma adequação entre os fins pretendidos e os meios disponíveis. (RUA, 1998, p. 02).

Isso quer dizer que uma política pública é sempre resultante de uma decisão política, já que envolve atividade política, contudo nem toda decisão política configura uma política pública.

Outra acepção é a de políticas públicas significando os programas de governo ou planejamento de ações dos órgãos públicos nas mais diversas e possíveis áreas. Sob este aspecto, é necessário observar que uma coisa é o atuar, o próprio fazer por parte do Estado, outra e anterior a esta última, é o programa de atuação, o planejamento da atuação estatal (JORGE NETO, 2009).

Entretanto, observa-se que nem sempre as ações do Estado vêm precedidas ou vinculadas a um programa ou a um planejamento anterior, ou ainda a uma lei, entendida aqui em sentido amplo. Com base nisso, observa-se que as políticas não possuem uma forma normativa específica, ou seja, apresentam uma multiformalidade. Em outras palavras, a exteriorização das políticas públicas não apresenta um padrão jurídico uniforme.

Normalmente são estabelecidas por meio da ação dos Poderes Legislativo e Executivo, seja por intermédio de leis, atos normativos infralegais ou ainda por outros atos administrativos. Estes, estabelecendo um programa governamental para uma área específica de atuação do Estado, mas nem sempre a formação de uma política é antecedida de um planejamento prévio (RUA, 2010).

Assim, saliente-se que, na maioria das vezes, a escolha das políticas públicas, sua formação, o estabelecimento de objetivos e metas a serem alcançados pertencem à esfera da discricionariedade dos Poderes Legislativo e Executivo. O que não os isenta de observar os objetivos e metas fixados nas normas constitucionais, muito importantes na medida em que devem determinar, condicionar e conformar toda a atividade estatal.

Por conseguinte, Mancuso (2001) ensina que política pública é a conduta comissiva ou omissiva da Administração Pública, em sentido largo, voltada à consecução de programa ou meta previstos em norma constitucional ou legal, sujeitando-se ao controle jurisdicional 
amplo e exauriente, especialmente no tocante à eficiência dos meios empregados e à avaliação dos resultados alcançados.

Acentue-se, que por um longo período de tempo, mais especificamente após a Revolução Industrial, é que se tornou necessária a conceituação de políticas públicas, uma vez que somente com o advento do Estado Social, "quando o Estado tomou para si uma série de funções que anteriormente desconhecia e que envolviam um atuar, o desenvolvimento de atividades em prol dos súditos, é que as políticas públicas entraram em pauta, [...]" (JORGE NETO, 2009, p. 51).

Percebe-se, pois, que para o Direito, o conceito de políticas públicas ganha relevo principalmente quanto à necessidade de se estudar a efetivação dos direitos fundamentais sociais. Entende-se, assim, por políticas públicas, um conjunto de ações coletivas voltadas para a garantia dos direitos de segunda dimensão, com base em um compromisso público que vise dar conta de determinadas demandas em diversas áreas expressando a transformação daquilo que é do âmbito privado em ações coletivas no espaço público.

\subsection{Política criminal como tipo de política pública}

A política criminal nasceu na segunda metade do século XVIII na Itália, por meio da publicação da obra de Beccaria, Dos delitos e das penas. Surgiu, assim, uma preocupação com formas eficazes de prevenção do delito e o conteúdo efetivo das leis para alcançar esta finalidade, Beccaria transpôs a teoria do direito penal da estrutura descritiva e submissa às funções declarativas da lei penal à busca de soluções para o problema da criminalidade.

Embora não goze de conceito unânime a expressão política criminal é vista pela maioria da doutrina jurídica como uma ciência. A arte de selecionar os bens jurídicos protegidos pelo Direito Penal bem como os caminhos de tal proteção, implicando na crítica dos valores e caminhos já eleitos (ZAFFARONI; PIERANGELI, 2009).

Entretanto, para certa parcela da comunidade penal, não há que ser vista na condição de ciência, pois apesar de se valer, muitas vezes, de dados científicos, estes são pertencentes a outros ramos do saber. Além de que muito do substrato (aperfeiçoamento da lei penal e conseqüentes modificações) da política criminal é oriundo de proposições carregadas de ideologias. 
Nesse contexto, entendendo-se a política criminal um tipo de política pública, esta “consiste na crítica do direito criminal, fundada em argumentos jurídicos ou ideológicos - ou em ambos -, tendente a modificar ou reformar os institutos e sistema de direito penal vigentes [...]” (SANTORO FILHO, 2000, p. 129).

Seria, ainda, o conjunto de princípios e recomendações para reagir contra o fenômeno delitivo através do sistema penal (instituições penal, judiciária e penitenciária) usando dos meios mais adequados no controle da criminalidade (BRITO, 2008).

$\mathrm{Na}$ busca de uma melhor compreensão, faz-se necessário percorrer, ainda que sucintamente, os principais movimentos político-criminais, concebidos também como modernas tendências de política criminal. O primeiro deles e talvez o mais conhecido é o movimento de lei e ordem originado nos Estados Unidos da América e chegado ao Brasil na década de 90.

Ele possui como principais adeptos políticos contrários às conquistas dos grupos defensores dos direitos humanos e a mídia sensacionalista voltada à população econômica e culturalmente menos favorecida. Prega a concepção de que a criminalidade e violência encontram-se em níveis avassaladores e incontroláveis e de que são fruto da legislação branda e dos inúmeros benefícios concedidos aos criminosos (ARAÚJO JÚNIOR, 1991).

Para os defensores deste movimento a pena é aplicada com caráter retributivo, ou seja, a sanção penal deve ser o instrumento utilizado com rigor e não deve ser vista como uma preocupação preventivo-especial de reintegração social do indivíduo. Ao contrário, deve permitir que o infrator seja castigado na medida do crime por ele cometido. Como medida punitiva, pugna-se, por exemplo, pela pena de morte para crimes considerados repugnantes e ainda a de prisão perpétua.

A respeito da privação de liberdade deve ser implementada por longos prazos com rígido regime de cumprimento reclamando ainda pela adoção de prisão provisória imediata aos crimes praticados. Nesse afã ganha espaço o princípio da culpabilidade ao invés da nãoculpabilidade combinado com uma redução máxima dos poderes do juiz e possibilidades de intervenção deste na concessão de benefícios ao preso por ocasião da execução de pena.

O movimento de lei e ordem representa um direito penal simbólico, ou seja, é dirigido às massas populares com o intuito de mascarar as ações governamentais distantes da real necessidade social. Sob este aspecto não se preocupa com a efetivação das medidas penais 
reivindicadas, mas apenas em passar a imagem para a mídia de que os problemas que incomodam a sociedade estão sendo resolvidos com fervor.

Segundo Zaffaroni e Pierangeli (2009) um segundo movimento de política criminal, chamado de Nova Defesa Social ou NDS, o qual foi primeiramente idealizado por Fillippo Gramática, prega a eliminação do direito penal em substituição à nova defesa social. Isso quer dizer que desaparecem as distinções entre pena e medida de segurança, dando lugar às providências de defesa social vinculadas às características pessoais a quem a elas deve se submeter.

A nova defesa social foi, entretanto, reformulada pelas idéias de Marc Ancel, que ao invés da eliminação do direito penal defendia a sua transformação e humanização. Para isso ressaltava que o direito penal não era o único instrumento de controle da criminalidade, mas carecia das outras ciências para que a defesa social pudesse se efetivar. Foi a corrente de pensamento político-criminal de maior aquiescência na sociedade científica do século XX e pretendia ser um sistema protetor tanto da sociedade como do delinquente pregando a manutenção do princípio da legalidade dos delitos e das penas (SANTORO FILHO, 2000).

Tem-se neste ponto instaurada uma violação ao princípio da legalidade e ao conteúdo dos direitos individuais, algo negativo, portanto, na medida em que a necessidade de defesa social sobrepõe-se à dignidade da pessoa humana.

Ademais a NDS prega um tratamento bifronte, ou seja, a descriminalização dos pequenos delitos e a criminalização das condutas contrárias aos direitos difusos e interesses relevantes do Estado. Entretanto, não oferece explicações acerca dos critérios que devam ser utilizados na interpretação da conduta como de menor ou maior potencial ofensivo culminando na retirada ou inclusão delas da esfera de proteção do direito penal (SANTORO FILHO, 2000).

Além disso, não oferece elementos precisos para delimitação do direito penal como ultima ratio bem como apesar de defender a ação ressocializadora da pena, não explica até onde pode chegar a ação educadora do Estado e os limites da defesa social apregoada. Assim, como ao permitir que seja utilizado o critério de proporcionalidade entre o dano social causado e a sanção a ser aplicada, abre a possibilidade de o direito penal atentar contra o valor da justiça confrontando desta maneira o próprio Estado Democrático de Direito.

O outro movimento de política criminal a ser destacado é o abolicionismo. Este, por 
sua vez, prega a eliminação de todos os sistemas punitivos, ou seja, uma transformação radical nas formas de se reagir contra a criminalidade tendo como maiores defensores Nils Christie e Louk Hulsman.

Santoro Filho (2000), leciona que para o abolicionismo o crime não existe, é decorrente dos processos sociais que dão sentido aos atos e são manifestações das classes mais poderosas em prejuízo das oprimidas. Consequentemente, a justiça criminal existe em favor da burocracia institucionalizada não solucionando os conflitos sociais e os efeitos preventivos e reeducativos jamais serão alcançados com a sanção penal.

Para os abolicionistas a grande maioria dos crimes não chega, sequer, ao conhecimento das instâncias penais de modo que não há motivos para se sustentar um sistema falido. Seria necessária, para eles, a abolição da justiça criminal e do próprio direito penal, o que ensejaria a busca de soluções por meio da elaboração de alternativas como, por exemplo, a participação da sociedade, a integração da vítima com o criminoso e a utilização da justiça civil e administrativa na resolução dos conflitos.

Observa-se, portanto, que todos estes movimentos possuem falhas na proposição de soluções aos conflitos de atuação da justiça criminal assim como carecem de refinamento nas ideias que pregam mesmo que em alguma medida até procurem explicar suas propostas. $\mathrm{O}$ fato é que não proporcionam a efetividade de uma política criminal capaz de atingir o fim de diminuição da criminalidade e violência, uma vez que se situam em posições extremistas.

\subsection{Políticas de segurança pública}

A segurança pública é um bem tutelado pela Constituição da República Federativa brasileira, mais especificamente no artigo 144. Este dispõe que se trata de dever do Estado assim como direito e responsabilidade de todos devendo ser exercida com o intuito de preservar-se a ordem pública, a incolumidade das pessoas e do patrimônio tendo como órgãos a polícia federal, a polícia rodoviária federal, a polícia ferroviária federal, as polícias civis, militares e corpos de bombeiros militares.

Nos dias atuais, a segurança pública se depara com um Brasil em situação de violência e criminalidade alarmantes. Dados estatísticos mostram que no ranking da UNESCO o Brasil ocupa o $3^{\circ}$ lugar no índice de assassinatos de jovens entre 15 e 24 anos de idade resultante de 
um aumento de 48 por cento na última década (UNESP, 2010).

Podendo mesmo ser considerada um dos maiores problemas da sociedade, a violência acontece desde o seio familiar até a própria ação dos profissionais que deveriam combatê-la. Entre suas causas figuram a situação de miséria em que vive a maior parte da população brasileira, culpa do modelo econômico globalizado baseado na lógica dos mercados, no qual o ser humano é visto como mercadoria.

Esse mal é, também, resultado do tráfico de drogas, responsável pelo enorme número de assassinatos praticados principalmente contra jovens, além da divulgação por parte da mídia de atitudes descomedidas de violência, seja em noticiários, filmes ou programas de televisão ou ainda das políticas de direito penal máximo que pregam sua aplicação em prima ratio.

Atualmente, diante desse cenário de crise instaurada, a segurança pública em grande medida sofre a ausência de investimentos do poder público, como por exemplo, recursos tecnológicos e pessoal devidamente treinado para agir adequadamente frente à situação.

Não se pode esquecer de que a problemática em torno da segurança pública sofre ainda hoje as influências de uma justiça criminal arcaica baseada em práticas sociais e institucionais tradicionais. A visão que se tinha era somente a de punição baseada na retribuição do mal causado como acontecia, por exemplo, no período colonial em que as principais eram o degredo e o açoite. Além, ainda, das influências econômicas das classes mais favorecidas da sociedade que, de certa forma, definiam todos os aspectos inclusive com relação às punições.

Não bastasse tudo isso, contou-se, ao longo dos anos, com inúmeras situações que acabaram impregnando na justiça criminal brasileira um cunho ditatorial no qual as instituições policiais eram distanciadas da população. Ainda hoje, mesmo que em menor proporção, e claro, em uma nova configuração, as corporações policias ainda resistem a uma aproximação de parceria com comunidades na luta contra o crime demonstrando técnicas ultrapassadas de atuação.

Entre estas, citem-se como exemplo, os sistemas tradicionais eminentemente repressivos que ainda dominam a área de segurança pública em todo o mundo. A técnica de se usar a violência para contê-la tem demonstrado uma maior geração de violência, portanto, insatisfatória. 
Sob esse aspecto, o conceito tradicional de segurança pública dá-se no sentido de que a função maior do Estado é garantir aos cidadãos incolumidade física e moral com base em um reflexo de convivência pacífica e harmoniosa entre os indivíduos. Hoje, um conceito propício seria o de que a segurança pública visa à ausência de perturbação e à disposição harmoniosa das relações sociais (JUCÁ, 2002).

Particularmente, as políticas públicas e, portanto de responsabilidade estatal, na área de segurança desempenham o papel de trazer mecanismos oriundos de um estudo qualificado, quais sejam as estratégias de ação capazes de não só garantir a punição do delito ora cometido, mas de se antecipar a ele numa atitude inteligente e perspicaz. Para isso, é necessário não somente atuação humana, propriamente dita, por meio dos profissionais de segurança, mas uma ação conjunta destes com pesquisadores e estudiosos do assunto.

Em tal contexto, a realidade vivida hoje no Brasil traduz sem qualquer dúvida que o fator segurança pública não dispõe de políticas capazes de propiciar a diminuição da violência e criminalidade ou ainda segundo os mais otimistas, sua extirpação. Ao contrário, denota que não se acertou até o presente momento quais ferramentas implementadas conseguiriam atingir esse fim.

Na lição de Jucá (2002), o que se tem observado é que as políticas de segurança pública estão se dando de dentro para fora, ou seja, partem das deliberações internas das áreas de segurança e tentam se instalar na sociedade sem antes estabelecer uma interação com esta. Ao contrário, estudos mostram que já não se pode falar em segurança pública sem a participação da sociedade. Pois como o próprio texto constitucional menciona, a segurança pública é um dever de todos.

Isso deixa claro que não somente o poder público é o responsável, mas a sociedade organizada é capaz de desempenhar um papel singular na diminuição da criminalidade e violência. Fator que requer a conscientização desta em sua responsabilidade pela segurança.

Sob essa perspectiva, por meio da ação conjunta entre poder público e sociedade, a instauração dos programas de policiamento comunitário baseada na elaboração de táticas preventivas, consequentemente, a abertura das instâncias policiais às dinâmicas externas. Além ainda, de uma formação transdisciplinar para os profissionais que atuam na área de segurança pública e a interligação destes com a produção acadêmica que emerge dentro das instituições voltadas para a segurança tem sido apontadas como políticas públicas eficazes na busca da tão almejada paz social. 
2.4 O garantismo penal

\subsubsection{Conceito e características}

A teoria do garantismo penal nasce como necessidade de resposta a uma das questões centrais da Filosofia do Direito na atualidade, qual seja o debate acerca da imensa disparidade entre teoria e prática em sede de direitos fundamentais do homem (ASSUNÇÃO, 2006). Em outras palavras, advém da divergência entre o plano normativo infraconstitucional e sua inefetividade quando em comparação com as previsões constitucionais.

A expressão garantismo vem do verbo garantir e tem como principal expoente Luigi Ferrajoli. Essa corrente faz parte do movimento de política criminal intitulado direito penal mínimo ou minimalismo penal, uma das acepções moderadas do movimento abolicionista. Significa dizer, que se trata de uma mínima intervenção com o máximo de garantias.

No entendimento de Maia (2000), o garantismo de Ferrajoli é uma forma de direito preocupada com os aspectos formais e substanciais que devem sempre existir para que o direito seja válido. A junção dos aspectos formais e substanciais teria o condão de resgatar a possibilidade de garantia efetiva aos sujeitos de direito de todos os direitos fundamentais existentes.

Segundo Calabrich, Fischer e Pelella (2010) o movimento garantista não se trata simplesmente de legalismo, uma vez que sua teoria se calca em um contexto de direito próprio de um Estado Democrático e Social. Em outros termos, não se pode mais ver um investigado ou réu na condição de um mero objeto de instrução processual e sim como um sujeito de direitos para o qual haja um julgamento coerente e embasado nas normas de validade constitucionais como uma condição de legitimidade.

Nessa perspectiva, o garantismo na condição de vertente do direito penal mínimo, pugna pela relegitimação do sistema penal empregando o minimalismo como um fim em si mesmo, ou seja, uma intervenção mínima limitadora da violência estatal

capaz de conter uma potencial anarquia punitiva advinda do abolicionismo propriamente dito. 
Leciona Assunção (2006) que o modelo penalístico garantista avalia o poder punitivo através de três eixos de análise: a) ponto de vista filosófico ou epistemológico com o fito de impor limitações ao arbítrio estatal; b) plano político ou axiológico avalia os limites (qualitativos e quantitativos) da ingerência estatal na esfera de liberdade dos cidadãos; e, finalmente, c) o enfoque jurídico ou normativo, através da construção de uma coerência entre o sistema penal punitivo e o ordenamento constitucional, bem como um referencial teórico balizado em uma principiológica superior.

Na busca da aferição de um sistema ser ou não garantista Ferrajoli (1998) aponta a necessidade de um referencial, ou seja, se somente forem observadas as normas estatais vigentes sobre direitos sociais no Brasil, maior seria o garantismo. Entretanto, se o ponto de observação for o da aplicabilidade, o grau de garantismo diminui.

Acrescenta, ainda, a noção de validade com base nos aspectos formal e substancial. Sob este ponto de vista, uma norma será válida não apenas pelo seu enquadramento formal às normas do ordenamento jurídico que lhe antecedem, mas é necessário validar elementos de conteúdo materiais como fundamento dela. Estes elementos, por sua vez, seriam os direitos fundamentais. Assim, norma vigente não dotada do caráter de validade estaria expurgada do ordenamento jurídico (FERRAJOLI, 1998).

Observa-se, então, que o garantismo penal busca estabelecer os elementos fundantes de um sistema punitivo democrático. Para isso, faz-se necessário que se assegure o máximo grau de racionalidade e confiabilidade do juízo e, portanto, de limitação do poder punitivo e de tutela da pessoa contra a arbitrariedade.

Em outros termos, a teoria do garantismo penal se apoia em princípios superiores limitadores das arbitrariedades do poder do Estado. Para essa teoria um ordenamento jurídico válido estaria condicionado à observância dos ditames referenciados no texto constitucional assim como o respeito e aplicabilidade dos direitos fundamentais consubstanciados na dignidade da pessoa humana.

\subsubsection{Princípios norteadores}

O sistema garantista aponta alguns princípios como alicerces. São dez axiomas fundamentais, os quais concatenados e harmonizados de forma sistemática oferecem um melhor entendimento e operacionalização da teoria. Trata-se mesmo de uma cadeia 
principiológica na qual se incorporam os postulados de legitimação do direito penal e dizem respeito ao proibir, ao castigar e ao julgar.

O primeiro deles é o princípio da retributividade (nulla poena sine crimine) ou da sucessividade da pena, segundo o qual o direito penal não pode se calar diante do delito cometido, fazendo-se necessária uma ação diante do crime, o que demonstra a não concordância com atitudes abolicionistas. $\mathrm{O}$ da legalidade (nullum crimen sine lege), nos sentidos estrito e lato, que aduz ser inviável condenar alguém e impor-lhe uma determinada penalidade sem que para isso haja uma expressa previsão legal adequada ao sistema constitucional vigente. O da necessidade (nulla lex 'poenalis' sine necessitate) ou economia do direito penal também conhecido como princípio da subsidiariedade. Devendo-se somente recorrer ao direito penal em último caso, ou seja, quando não houver nenhum outro meio capaz de solucionar o conflito. É a utilização do direito penal como ultima ratio, “[...] uma vez que constitui a mais violenta manifestação do poder estatal sobre a liberdade individual, a justificação racional do sistema punitivo exige que a atuação do aparelho repressivo esteja condicionada à extrema [...] necessidade.” (SILVA, 2008, p. 67).

Continuamente, o princípio da lesividade ou da ofensividade (nulla necessitas sine injuria) aduz a necessidade de efetiva lesão ao bem jurídico tutelado de modo que advenha da Constituição a autorização de punição em caso de descumprimento. Ainda o princípio da materialidade (nulla injuria sine actione) demonstrando a necessidade de aspectos substanciais de ocorrência do fato delituoso; bem como o princípio da culpabilidade (nulla actio sine culpa), o qual denuncia a necessidade de responsabilização do agente que praticou o ato e para isso a devida comprovação de sua autoria, o que em caso contrário, enseja a aplicação da máxima do in dubio pro reu.

Nesse contexto, o princípio da jurisdicionalidade (nulla culpa sine judicio) segundo o qual o devido processo legal deve ser direcionado por autoridade investida das competências constitucionais estipuladas. Ainda, o princípio acusatório (nullum

judicium sine accusatione), isto é, a nítida separação das pessoas responsáveis pela acusação e julgamento. Assim como o princípio do encargo da prova (nulla accusatio sine probatione), ou seja, a obrigatoriedade da acusação provar a responsabilidade criminal do agente não se 
impondo, portanto, ao réu o encargo de ser ele inocente. E também o princípio do contraditório (nulla probatio sine defensione) que impõe a necessidade de observância de saber o réu sobre o que está sendo acusado de maneira que lhe seja admitida a ampla defesa.

Sob essa ótica, tendo como base o sistema garantista, pode-se falar em ordenamento baseado no direito penal mínimo - quando mais próximo se estiver do asseguramento das referidas garantias - ou no direito penal máximo - quanto menos garantias asseguradas forem.

Percebe-se que todos esses princípios já são consagrados no texto constitucional, o que demonstra serem de aplicação cogente. Entretanto, o que nem sempre ocorre é sua efetivação prática, ou seja, a Constituição da República brasileira é garantista na medida em que apregoa todos eles e os tem como pilares de observância obrigatória, mas como visto anteriormente, o grau de garantismo é medido com base em sua aplicabilidade e, se na prática não está sendo efetivado na proporção em que a teoria determina, então não se tem garantismo.

\subsubsection{Acepções da doutrina garantista - validade e efetividade}

Para uma teoria geral do garantismo são apontados três significados ou pontos de vista determinantes. Numa primeira acepção o garantismo expressaria um modelo normativo de direito, expressamente no que diz respeito ao direito penal, o modelo de estrita legalidade, próprio do estado de direito caracterizando-se como um sistema cognitivo ou de poder mínimo (SILVA, 2008).

Ainda pertencente a esta, mas num plano político, denota uma técnica de tutela capaz de minimizar a violência e de maximizar a liberdade e, sob um plano jurídico, como um sistema de vínculos impostos ao poder de punir do Estado em garantia dos direitos dos cidadãos (CALABRICH et al., 2010).

Segundo Ferrajoli (1998), numa segunda acepção, o garantismo relaciona-se a uma teoria jurídica da validade e efetividade como duas categorias distintas entre si e também no que se refere à existência e vigência das normas. Nessa perspectiva, o garantismo expressa uma aproximação teórica que mantém separados o ser e o dever ser no direito. Compreendese, que: 


\begin{abstract}
En una segunda acepción, garantismo designa una teoría jurídica de la validez y de la efectividad como categorías distintas no sólo entre sí, sino también respecto de la existencia o vigencia de las normas. En este sentido, la palabra garantismo expresa una aproximación teórica que mantiene separados el ser y el deber ser en el derecho; e incluso propone, como cuestión teórica central, la divergencia existente en los ordenamientos complejos entre modelos normativos (tendencialmente garantistas) y prácticas operativas (tendencialmente anti-garantistas), interpretándola mediante la antinomia -dentro de ciertos límites fisiológica y fuera de ellos patológica- que subsiste entre validez (e inefectividad) de los primeros y efectividad (e invalidez) de las segundas. (FERRAJOLI, 1998, p. 852).
\end{abstract}

Nota-se, pois, que, há grande diferença entre direito válido e efetivo, ou seja, são dois mundos de existência a serem observados: o do plano normativo e o do plano concreto. Significa ainda dizer que o julgador não tem a obrigação de aplicar as leis inválidas ou incompatíveis com o ordenamento constitucional ainda que vigentes.

Sob essa ótica, para uma melhor compreensão, faz-se salutar a distinção entre justiça, vigência, validade e eficácia. Segundo Cademartori (1999) uma norma é justa quando ela satisfaz de maneira positiva um critério de valoração ético-político. É vigente quando não possui vícios formais, ou seja, foram obedecidos aos procedimentos prescritos no tocante a sua promulgação e sujeitos competentes. É válida quando imunizada contra vícios materiais, isto é, não se acha contradita com nenhuma norma hierarquicamente superior e, eficaz quando é observada tanto por seus destinatários quanto pelos órgãos responsáveis por sua aplicação.

Acrescenta Ferrajoli (1998) que o aspecto formal do direito existente no procedimento prévio age como um pressuposto legítimo de existência de uma norma estatal, condição necessária para sua validade no ordenamento jurídico. O que por si só não é suficiente, sendo, portanto, necessário o elemento substancial do universo jurídico, ou seja, os elementos materiais, os direitos fundamentais.

É sob essa visão que se assenta a necessidade de observância de uma norma, em sentido lato, e, portanto, de uma política de segurança pública, vista aqui como um conjunto de diretrizes capazes de definir a atuação dos profissionais de segurança no combate à violência e criminalidade. Em outros termos, nada adianta o texto formalizador destas políticas direcionar como deve ser se não forem aplicadas efetivamente na prática cotidiana. E, além de existentes, estas devem corresponder ao texto constitucional sob pena de não serem consideradas válidas. 
Por conseguinte, a terceira acepção da teoria garantista se refere à designação de uma filosofia política impondo ao Direito e ao Estado o ônus da justificação externa com base nos bens e interesses tutelados (CALABRICH et al., 2010). Isso quer dizer que a relação entre o garantismo e a filosofia política se baseia na cisão entre o direito e a moral identificando a necessidade de legitimação formal interna do poder punitivo.

\subsubsection{Principais críticas}

Várias são as críticas em torno da teoria garantista. Algumas com base no fato de estar enquadrada em uma das vertentes do abolicionismo e, portanto, ausência de qualquer sistema punitivo, o que para muitos evidencia uma situação de anarquia social. Outras baseadas no entendimento de que só se pode falar em contenção de violência e criminalidade se forem diminuídos ao máximo qualquer espécie de benefício aos infratores e, desta forma, aplicação de penas mais severas com o intuito de reprimi-los ao máximo.

Em meio a toda essa discussão se é cabível ou não adotar medidas garantistas, Cláudio Leiria ao responder a indagação sobre o motivo da quantidade de delitos aumentar sem que os criminosos sejam punidos e também porque os delinquentes cometem crimes graves e permanecem presos por pouco tempo, afirma que isso se dá em virtude de que "[...] os criminosos têm inúmeros protetores, espalhados nos meios jurídicos e variados segmentos da nossa sociedade.” (LEIRIA, 2006, p. 1).

Acrescenta que teses jurídicas como a inconstitucionalidade da reincidência, das nulidades por insignificância, assim como da vedação da progressão de regime para crimes hediondos e ainda do reconhecimento de crime de bagatela para valores que segundo ele, são consideráveis, entre outros, exemplos claros de proteção aos criminosos e, em grande medida, oriundos da tese preferida, ou seja, o garantismo penal.

Para ele a democracia acha-se em perigo na medida em que as interpretações benevolentes das leis criminais trazem a desesperança ao povo com o sistema de justiça atual, além, ainda, do pesadelo garantista no qual se encontra o Brasil.

Outra crítica parte do vazio ontológico que permeia a doutrina garantista, ou seja, apesar de ser uma teoria comprometida com ideais democráticos, indaga-se qual critério para se fixar o conteúdo de direito fundamental. Além disso, a própria tentativa de se fixar um conteúdo a esta categoria de direitos, esbarra-se no formalismo justamente pelo vazio que 
caracteriza de fato os direitos fundamentais. Preocupação que se torna maior quando o vazio ontológico serve de base para ideologias distintas dos ideais democráticos, ou seja, regimes totalitários traçando uma ideia do que para eles seja fundamental (MAIA, 2000).

Ora, o fato é que em muito não se entende a teoria do garantismo penal da forma como Ferrajoli tem tentado explicar. Talvez o fato de ela estar classificada como uma vertente do abolicionismo tem provocado resistência em sua aceitação. Mas é notório que o próprio ordenamento jurídico brasileiro possui características garantistas em meio a punições voltadas para o direito penal máximo, a exemplo, os princípios constitucionais penais elencados no texto constitucional.

Observa-se, então, que o sistema penal brasileiro abarca as várias medidas sugeridas pelos movimentos de política criminal, não se aplicando apenas a um deles. Ora se vê medidas garantistas, ora se vê medidas de direito penal máximo, o que denuncia a necessidade de aprofundamento dos estudos acerca do tema, principalmente na base de fundamentação legislativa, ou seja, as normas que, consequentemente, direcionem as políticas públicas.

\section{CONCLUSÃO}

Num estado democrático de direito devem-se privilegiar a defesa e proteção dos direitos fundamentais alicerçados no texto constitucional, principalmente os que dizem respeito aos valores construídos na sociedade.

Dentre estes o direito à segurança pública evidencia-se como um instrumento de conformação do ciência jurídica fundamentada na valorização da dignidade da pessoa humana, uma vez que procura estabelecer mecanismos que permitam ao ser humano ver-se respeitado. Na esfera do Direito Penal, tal questão se dá como de extrema relevância, uma vez que a segurança pública, refere-se a um dever do Estado e direito de todos dentro da coletividade.

A presente pesquisa teve como norte o referido direito consubstanciado nos artigos 144 e seguintes da Constituição da República brasileira, a qual outorga aos indivíduos a garantia de uma prestação positiva por parte do Estado, revelando a transição das liberdades formais abstratas para as liberdades materiais concretas. Ou seja, trata-se de uma intervenção por parte do ente estatal na esfera cotidiana permitindo ao cidadão uma existência digna 
dentro da sociedade.

Sob esse enfoque, com base na explanação sobre políticas públicas, dentre elas as criminais, mais especificamente as de segurança pública, objetivou-se primordialmente refletir sobre a adoção de tais políticas com caráter garantista no Direito Penal brasileiro.

Demonstrou-se a necessidade de se implementá-las, de modo que ao serem adotadas propiciem o prevalecimento das determinações do texto constitucional, principalmente, quanto à efetivação dos princípios que o rege.

Concomitantemente foram demonstrados alguns movimentos de política criminal bem como suas características abordando com maior critério a teoria garantista, a qual prima pela diminuição da distância entre a norma e a prática na realidade cotidiana. Propondo ainda uma reflexão no que concerne à efetivação ou não dos princípios constitucionais de aplicação do Direito Penal.

A opção pelo tema deu-se, portanto, em virtude da necessidade de se falar sobre a maneira como a política criminal - mecanismo capaz de nortear a aplicação da legislação penal e determinar as diretrizes sobre as quais deve ser conduzida a atuação do Direito Penal no Brasil - vem sendo implementada. Em outros termos, há a necessidade de se expor acerca de políticas criminais de segurança pública embasadas na visão principiológica defendida pela Constituição da República brasileira em meio ao alto índice de violência e criminalidade atuais.

Sob essa ótica, a pesquisa desenvolvida permite a observância de que não adianta tratar o aspecto da segurança pública com base em movimentos político-criminais geradores de maior incidência de crimes. Embora, não se queira com isso abordar a problemática por meio de práticas abolicionistas capazes até de desestruturar o ordenamento jurídico-penal vigente. $\mathrm{O}$ que se verifica, a partir dessa análise, é uma maior concordância por parte dos estudiosos do tema de que em se tratando de aspecto tão importante e delicado dentro de uma sociedade, é preferível que se prime pela adoção de mecanismos aptos a preservar a integridade e o respeito ao ser humano.

Assim, apesar de o modelo teórico garantista ser classificado como uma vertente do abolicionismo, percebe-se que o mesmo, pelo menos em sua forma originária, busca a preservação de políticas criminais alicerçadas no texto constitucional, respeitadoras dos princípios ali aduzidos e, portanto, aptas a diminuir a distância entre o texto normativo e a realidade prática. 
Sob essa perspectiva, sabendo-se que para uma sociedade existir plenamente faz-se necessária uma estrutura social sólida e prestacional por parte do Estado, políticas de segurança pública bem planejadas e efetivas não só minimizam os índices de violência, mas também são instrumentos aptos a favorecer o desenvolvimento da coletividade. Daí a importância de investimento estatal em sua formulação.

Logo, foi possível corroborar-se, cautelosamente, entretanto, com a corrente de visão garantista, uma vez que a atuação do poder público, na esfera penal, deve-se fortalecer na necessidade de efetivação dos princípios constitucionais penais buscando tornar reais mecanismos aptos a combater o crime de maneira que este não venha a ser ainda mais financiado.

Foi neste contexto dinamizador que a pesquisa situou-se. Isto é, na abordagem das políticas de segurança pública, cuidou-se de, à luz do ordenamento jurídico brasileiro, demonstrar a situação em que elas se encontram e o que seria necessário, mesmo que em caráter exemplificativo, portanto, jamais com intuito de esgotar o tema, fazer para que venham atingir o fim de concretizar o direito à segurança, tema que requer, portanto, maior aprofundamento inclusive na ótica proposta, de cunho garantista.

\section{REFERÊNCIAS}

ARAÚJO JÚNIOR, João Marcello de. Os grandes movimentos da política criminal de nosso tempo - aspectos. In: ARAÚJO JÚNIOR, João Marcello de (Org.). Sistema penal para o terceiro milênio: atos do colóquio Marc Ancel. 2. ed. Rio de Janeiro: Revan, 1991.

ASSUNÇÃO, Marlize Daltro. Teoria geral do garantismo: considerações preliminares. Jus Navigandi, n. 970, 2006. Disponível em: 〈http://jus.com.br/revista/texto/8037. html〉. Acesso em: 11 fev. 2010.

BRASIL. Constituição (1988). Constituição da República Federativa do Brasil. São Paulo: Saraiva, 2010.

BRITO, Iuri Teixeira. A política criminal nos dias de hoje. 2008. Disponível em: < http://www.artigonal.com/legislacao-artigos/a-politica-criminal-nos-dias-de-hoje437028.html >. Acesso em: 25 mar. 2010. 
BUCCI, Maria Paula Dallari. O conceito de política pública em direito. In: BUCCI, Maria Paula Dallari (Org.). Políticas Públicas - reflexões sobre o conceito jurídico. São Paulo: Saraiva, 2006.

CADEMARTORI, Sérgio. Estado de Direito e Legitimidade: uma abordagem garantista. Porto Alegre: Livraria do advogado, 1999.

CALABRICH, Bruno; FISCHER, Douglas; PELELLA, Eduardo. Garantismo penal integral. Salvador: Juspodivm, 2010.

COMPARATO, Fábio Konder. Ensaio sobre o juízo de constitucionalidade de políticas públicas. In: BANDEIRA DE MELLO, Celso Antônio (Org.). Estudos em homenagem a Geraldo Ataliba: direito administrativo e constitucional. São Paulo: Malheiros, 1997.

FERRAJOLI, Luigi. Derecho y razón: teoria del garantismo penal. Madrid: Trotta, 1998.

JORGE NETO, Nagibe de Melo. O controle jurisdicional das políticas públicas concretizando a democracia e os direitos sociais fundamentais. Salvador: Juspodivm, 2009.

JUCÁ, Roberta Laena Costa. O papel da sociedade na política de segurança pública. Jus Navigandi. n. 60, 2002. Disponível em: <http://jus.com.br/revista/texto/3525.html>. Acesso em: 11 mar. 2010.

LEIRIA, Cláudio da Silva. Os protetores dos criminosos. Jus Navigandi. n. 1244, 2006.

Disponível em: <http://jus.com.br/revista/texto/9209>. Acesso em: 24 mar. 2010.

MAIA, Alexandre da. O garantismo jurídico de Luigi Ferrajoli: notas preliminares. Revista de informação legislativa, Brasília, v. 37, n. 145, p.41- 46, jan./mar. de 2000. Disponível em: <http://www2.senado.gov.br/bdsf/item/id/553 >. Acesso em: 13 fev. 2010.

MANCUSO, Rodolfo de Camargo. A ação civil pública como instrumento de controle judicial das chamadas políticas públicas. In: MILARÉ, Edis (Org.). Ação Civil Pública: Lei 7.347 - 15 anos. São Paulo: Revistas dos Tribunais, 2001.

RUA, Maria das Graças. Análise de Políticas Públicas: Conceitos básicos. In: RUA, Maria das Graças; CARVALHO, Maria Isabel V. de (Org.). O estudo da política: tópicos selecionados. Brasília: Paralelo 15, 1998.

SANTORO FILHO, Antonio Carlos. Bases críticas do direito criminal. Leme: Led, 2000. 
SILVA, Ana Claudia da. Políticas de (Des)Criminalização. 250f. Dissertação (Mestrado em Direito) - Coordenação de Pós-graduação em Direito da Universidade Federal do Paraná, Curitiba, 2008. Disponível em: http://dspace.c3sl.ufpr.br:8080/dspace/bitstream/1884/18292>. Acesso em: 14 mar. 2010.

UNIVERSIDADE DO ESTADO DE SÃO PAULO - UNESP. Observatório de segurança pública. Apresenta informações que procuram facilitar o acesso sobre segurança pública no Estado de São Paulo. Disponível em: 〈http://www.observatoriodeseguranca.org>. Acesso em: 12 fev. 2010.

ZAFFARONI, Eugenio Raúl; PIERANGELI, José Henrique. Manual de direito penal brasileiro. 8. ed. São Paulo: Revista dos Tribunais, 2009. 